RESEARCH AND PRACTICE

\title{
Social and behavioral implications of National Collegiate Athletic Association sickle cell trait screening: The athletes’ perspective
}

Raymona H. Lawrence, DrPH, MPH, MCHES ${ }^{1}$, Alison Scott, $\mathrm{PhD}^{2}$, Carlton Haywood Jr., PhD, MA³, Kayin Robinson, $\mathrm{MPH}^{4}$, Mondi Mason, $\mathrm{PhD}, \mathrm{MPH}^{5}$

${ }^{1}$ Jiann Ping Hsu College of Public Health, Georgia Southern University, Statesboro, GA; ${ }^{2}$ Department of Kinesiology and Health Sciences, The College of William and Mary, Williamsburg, VA; ${ }^{3}$ The Johns Hopkins Berman Institute of Bioethics, Johns Hopkins University, Baltimore, MD; ${ }^{4}$ College of Public Health, University of Georgia, Athens, GA; ${ }^{5}$ City and County of Denver Department of Environmental Health

\begin{abstract}
Background: In August 2010, the National Collegiate Athletic Association (NCAA) implemented a policy mandating sickle cell trait (SCT) testing for all Division I collegiate athletes. Subsequently, all Division II-III athletes were also compelled to undergo SCT testing. This decision has met with controversy among healthcare providers, researchers, and sickle cell advocates. However, there is little information concerning the athletes' perspective of this policy. The purpose of this paper is to report the findings of a qualitative study that explored college athletes' perceptions of sickle cell trait SCT, NCAA policies on SCT testing, and potential implications of SCT screening.
\end{abstract}

Methods: The participants were eighteen male and female athletes (ages 18-24), members of NCAA-governed teams who were on the study campus from April-August 2010. Athletes participated in focus groups that gathered their perceptions of the SCT, the NCAA SCT policy, and social and behavioral implications of a SCT diagnosis.

Results: Athletes lacked knowledge of the SCT and the implications of a positive screening test result, desired health education about SCT, were conflicted about sharing health information, and feared loss of playing time if found to carry the SCT.

Conclusions: The study revealed athletes’ perceptions of the SCT and mandated NCAA SCT testing that should be addressed by college health professionals.

Keywords: NCAA, sickle cell trait, athlete, discrimination, education

\section{INTRODUCTION}

\section{Background}

The 2006 death of Dale Lloyd, an athlete at Rice University who carried the sickle cell trait (SCT), led to major revisions of the SCT screening policy of the National Collegiate Athletic Association (NCAA). Lloyd's collapse at football practice and subsequent death were attributed to complications from SCT. Lloyd's family sued the NCAA and Rice University. One of the stipulations of the resulting settlement was that the NCAA require SCT testing for all Division I athletes. Therefore, in August 2010, the NCAA implemented a policy mandating SCT testing for all Division I collegiate athletes. Subsequently, all Division IIIII athletes were also compelled to undergo SCT testing. Routine SCT testing is now part of the pre-participation medical exam that all NCAA athletes complete, except in cases where the athlete provides results of a prior SCT screening test or signs a written release (Hosick, 2010).

There is a distinction between the SCT and sickle cell disease (SCD). The SCD and SCT primarily affect African Americans, but not exclusively. Between 80,000 and 100,000 Americans have SCD (Brousseau et al, 2010;
Hassell, 2010). SCD occurs in about one in every 500 African-American births, compared to 1 in every 36,000 Hispanic-American births, and 1 in every 100,000 Caucasian births (National Heart Lung and Blood Institute (NHLBI), 2014). People with SCD may experience episodes of sudden pain throughout the body, severe anemia, eye problems, and organ failure (NHLBI, 2014). Therefore, SCD can cause substantial physical, social, and financial burdens and is associated with lower life expectancy in sufferers (Elmariah, 2014). SCT, however, is generally regarded as a benign condition. People with SCT do not typically experience the anemia or joint pains experienced by those with SCD, and usually have a normal life expectancy. About two million Americans, or one in 12 African Americans, carry the SCT (NHLBI, 2014).

\section{Complications of SCT}

Medical complications from the SCT are rare. However, it has been associated with hematuria (blood in the urine), hyposthenuria (inability to concentrate urine), splenic infarction (tissue death due to lack of oxygen) at high altitudes, and death from extreme exertion, as in the Lloyd case (Harrelson, 1995; Kark, 1987; Kerle, 1996). Harmon et al (2012) analyzed NCAA data from 2004-08 and found 
that SCT carriers were 37 times more likely to die from exertion than athletes without the SCT. Despite these findings, there continues to be much debate in the scientific community surrounding the link between the SCT and exercise-related morbidity and sudden death (Thompson, 2013). The clinical manifestations of the SCT as they relate to athletic participation have been the main focus of scholarship on the NCAA policy. However, evidence-based information on the social and behavioral aspects of the policy is lacking. Nevertheless, the physiological aspects of trait have been described (Connes, 2008; Eichner, 2011; Harmon, 2012; Schommer, 2012, Thompson, 2013). The focus this paper is on the historical facets of SCT screening and the social and behavioral implications of screening from the points of view of athletes.

\section{Opposition to the SCT Screening Policy of the NCAA}

Literature concerning the mandatory SCT screening policy of the NCAA constructs it as a social and clinical experiment (Bonham, 2012), notes the inconsistency of delivery of SCT health education, addresses the possibility of discrimination towards athletes who are SCT carriers (Grant, 2011) and raises concerns about protection of individual rights of athletes (Jordan, 2011). Many suggest that scientific evidence to support the policy's underlying assumptions of cause and effect between the SCT and death is lacking (Jordan, 2011).

\section{History of SCT screening}

The lack of scientific evidence linking the SCT to morbidity and sudden death is a critique of the NCAA policy, but discomfort with the policy is also grounded in the troubled history of SCT screening. The history of sickle cell disease and trait (SCD/T) screening has been fraught with claims of discrimination, genocide, and general skepticism, especially among African Americans. The Sickle Cell Disease Control Act of 1972 (Hill, 1994) was designed to increase knowledge and awareness of SCD among African Americans and other ethnic groups. However, it also provoked racialized controversies (Hill, 1994; Wailoo, 2001). Further criticisms of early sickle cell screening programs included their lack of sensitivity to issues of race, controversy surrounding the accuracy and validity of the early screening tests, and inadequate protection of patients' rights (Markel, 1992). SCT carriers have also been subject to discrimination. For example, carriers have been denied employment after a positive test (United States Congress, 1990) and, prior to 1981, the United States Air Force Academy excluded African-Americans with sickle cell trait because of concerns over service-connected disability (Scott, 1982). Further, potential links between the SCT and lost athletic opportunity (via reduced playing time) raises concerns about discrimination, since African Americans carry the SCT disproportionately to their Caucasian and Latino peers.

The analysis presented here is pertinent to collegiate athletic trainers, coaches, physicians, and health educators (hereafter referred to as "college health professionals"). These professionals should be aware of the social and behavioral implications of this policy when implementing SCT screening practices on their respective campuses. While the existing literature examines SCT testing from the perspectives of professional organizations (APHA, SCDAA, and ASPHO), pediatricians (Koopmans, 2011) researchers (Bonham, 2010; Grant, 2011; Jordan, 2011; Thompson, 2013), and sports medicine providers (Acharya, 2011), the perspectives of athletes - the individuals directly affected by this policy-have not been adequately examined. This article moves beyond the dominant emphasis on clinical manifestations of the SCT in athletics by focusing on the social and behavioral implications of SCT testing for NCAA athletes.

Between April and August 2010, a mixed methods study (Lawrence, 2010) was conducted at a mid-sized university in the southern United States to explore college athletes' perceptions of SCT and NCAA policies on SCT testing and the potential implications of NCAA SCT screening policies. The quantitative portion of the study surveyed 259 athletes and examined race- and genderrelated differences in athletes' perceptions regarding SCT risk and level of concern about lost playing time following diagnosis. These results are reported elsewhere (Lawrence \& Shah, 2014). Following the quantitative portion, the qualitative portion of the study was implemented to examine perceptions held by athletes. This paper reports the findings of the qualitative portion, which used focus groups to explore college athletes' perceptions of the SCT and NCAA policies on SCT testing. These perceptions are informative of the social context of implementation of SCT screening in organized sports.

\section{METHODS}

The three prominent research questions were:

1) What are the perceptions of collegiate athletes of the SCT and NCAA SCT testing?

2) Do perceptions of collegiate athletes of the SCT and NCAA SCT testing differ by race?

3) What are the implications of an SCT diagnosis from the perspectives of athletes?

The theoretical framework for this study drew insights from Critical Race Theory (CRT) (Delgado, 2001) and the Health Belief Model (Strecher \& Rosenstock, 1996). CRT is a conceptual lens used to evaluate racism and distribution of power and privilege amongst racial groups within institutions and society. The basic tenets of CRT posit: 1) racism is normal (that is, a part of the everyday lives of persons of color); 2) interest convergence (i.e., because racism advances the interests of the majority (materially) and the minority (physically) there is little incentive to eradicate it); 3) race is a social construction (society and culture influence mental constructs and stereotypes around race); and 4) differential racism (each race has a unique history). In this context, CRT aims to provide minorities a "voice" in both academic and public arenas (Delgado \& Stefancic, 2001). For our purposes, CRT draws attention to how race may affect athletes' perceptions of the SCT and SCT screening, and allows location of some of the individual perceptions highlighted by this study in a larger context of (American) institutionalized racism. 
The Health Belief Model (HBM) is a value-expectancy theory that helps predict why individuals take action (or not) to perform specific health behaviors, such as preventive screening for certain illnesses or conditions (Strecher \& Rosenstock, 1996). Constructs of the HBM were used to determine perceptions about susceptibility, severity, benefits, and barriers to SCT screening and to determine perceptions of athletes regarding SCT testing.

The study was conducted from April-August 2010 at a coeducational university in the southern United States. At the time of the study, nearly 20,000 students were enrolled: 29.9\% (4,981) were minorities, with 22.1\% (3,874 students) being African American. Approximately 270 athletes were on the intercollegiate athletic teams of the university. The athletic program mandated SCT screening for all of its student athletes, regardless of ethnicity, beginning in 2009 (prior to the NCAA's mandatory SCT screening policy and the implementation date of this study). The views of athletes about both voluntary and mandatory SCT testing were elicited.

Eligibility requirements included being a male or female athlete 18 years of age or older and a current member of an NCAA-governed athletic team on the study campus. All athletes who met these requirements were eligible to participate in the focus groups regardless of prior screening history or SCT status. Athletes to participate in focus groups were recruited by strength and conditioning coaches. The study coordinator developed a recruitment guide that was given to coaches to aid in athlete recruitment. A purposeful sample of participants was sought to maximize variation in perspective by race, sex, and sport. The university's Institutional Review Board (IRB) approved the study.

A focus group guide was used to structure the discussions. Initial questions allowed participants to reflect on their general experiences as college athletes. The HBM provided the framework for the next set of questions, which asked athletes about their knowledge of the SCT, their perceptions of voluntary and mandatory SCT testing, and their perceptions of the implications if they were found to carry the SCT during a pre-participation health screening. Since the SCT primarily affects African Americans, the athletes' perceptions of race relations and racism on campus and in athletics were also discussed. Critical Race Theory (Delgado \& Stefancic, 2001) informed the design of this group of questions.

Each focus group lasted for about one hour and was held in the evenings in a meeting room that was used specifically for athletics programs. The focus group facilitator administered an informed consent process to the participants. Because the SCT primarily affects African Americans, focus groups were separated by self-identified race to provide a means to compare within- and betweengroup differences in responses. Three focus groups involving 18 athletes were conducted. Table 1 illustrates the composition of each of the focus groups.

Table 1: Focus Group Demographics

Demographic Variables

\begin{tabular}{|c|c|c|c|c|c|}
\hline & Male & Female & $\begin{array}{c}\text { African } \\
\text { American }\end{array}$ & Caucasian & $\begin{array}{c}\text { Sport } \\
\text { Played/Athletes } \\
\text { Representing } \\
\text { Sport } \\
\end{array}$ \\
\hline $\begin{array}{l}\text { Focus Group } 1 \\
\quad(\mathrm{~N}=9)\end{array}$ & 3 & 6 & 0 & 9 & $\begin{array}{l}\mathrm{FB}(3) \\
\mathrm{VB}(4) \\
\mathrm{CC}(1) \\
\mathrm{BB}(1)\end{array}$ \\
\hline $\begin{array}{l}\text { Focus Group } 2 \\
\quad(\mathrm{~N}=9)\end{array}$ & 4 & 5 & 9 & 0 & $\begin{array}{l}\mathrm{FB}(4) \\
\mathrm{VB}(1) \\
\mathrm{BB}(4)\end{array}$ \\
\hline $\begin{array}{l}\text { Focus Group } 3 \\
(\mathrm{~N}=11)\end{array}$ & 2 & 9 & 5 & 6 & $\begin{array}{l}\mathrm{FB}(2) \\
\mathrm{VB}(3) \\
\mathrm{CC}(1) \\
\mathrm{BB}(5)\end{array}$ \\
\hline
\end{tabular}

Note: FB=Football; VB=Volleyball; $\mathrm{CC}=$ Cross Country; $\mathrm{BB}=$ Basketball

Focus group 1 consisted of athletes who self-identified as Caucasian, and focus group 2 consisted of athletes who selfidentified as African American. Focus group 3 was a mixedrace group that consisted of individuals in groups 1 and 2 who volunteered to return for a follow-up group. The purpose of this group was to gain clarity on responses given in the contexts of groups 1 and 2, and to assess group dynamics and variation in response to questions, especially those concerning race, when the group was of mixed race. Participants were given an opportunity to contribute other information or opinions before each focus group concluded.
No incentives were used to recruit the athletes because it is against NCAA policy to incentivize college athletes.

All focus group discussions were audio recorded. Recordings were transcribed verbatim, coded, and analyzed thematically using Atlas.ti 6.2 qualitative data analysis software (Atlas.ti, 2010). A codebook, developed a priori, employed constructs drawn from the study's theoretical framework. Three researchers coded the transcripts and met periodically to resolve any discrepancies. To assure data integrity (reliability and validity), coder reliability 
techniques developed by Kirk and Miller (1986) were implemented. Lincoln and Guba's (1985) trustworthiness criteria were used to evaluate the credibility of study findings. To protect privacy of participants, all data were deidentified.

\section{RESULTS}

Analysis of focus group transcripts, digital recordings, and field notes yielded various themes related to SCT policy and testing, control of health information and the racial climate in college sports at the university. Themes identified included: 1) misconceptions of the SCT; 2) positive views of mandatory SCT testing; 3) desire for health education regarding the SCT; 4) race issues in campus athletics; and 5) communication conflict and fear of lost playing time. Each of these themes is explored below.

\section{Misconceptions of the SCT}

Athletes had misconceptions of the SCT and were unaware of its history as it relates to race. Although they knew that African Americans were more likely to be carriers, much of their knowledge about the SCT was general in nature. For example, athletes said, "It's predominately in African Americans," or "It's something in the blood." Athletes were uncertain about medical risks or consequences of having the trait, although they knew that athletes with the SCT might get "winded quicker." One athlete stated, "It's not as serious as the actual disease." Athletes demonstrated basic understanding of the genetic inheritance pattern of the trait by making statements such as, "It's not always passed down through the generations. You know your father might have it [SCT], but that doesn't mean you will have it...and even both your parents might have it." Many statements about the SCT reflected exposure to education about SCD/T at some point. However, these statements illustrate the vagueness of knowledge about the SCT. Athletes made comments such as, “...their blood cells are like split in half or have holes in them or something," likely in reference to the sickling of blood cells in SCD. Other statements hinted at the distinction between the SCT and SCD, though not completely accurately. For example, “...with [the sickle cell] trait, you have the potential to carry the disease," and "If you're a carrier, you have spots of it throughout your body and it's not necessarily full-on spread.” Athletes also had the misconception that SCD/T only occurred in African Americans and agreed that "Caucasians can’t get it.”

\section{Positive Views of Mandatory SCT Testing}

Although athletes held misconceptions of the SCT, they understood the rationale for the mandatory SCT screening policy and thought that greater awareness of SCT, both generally and individually, was a good thing. When asked how they felt about the policy, participants overwhelmingly responded, “It's good!” or, "It’s smart.”

Other comments expressed a sense of indifference about the policy, viewing it simply as, "something else we gotta do for the NCAA. It's one box to check among many before you can get along to the business of playing your sport." An athlete further explained why athletes might be passive about SCT testing:
"I don't think it affects a lot of athletes because they are just gonna look at it as something else we gotta do for the NCAA. So let's go on and get it done and go on about our business. 'Cause in the pre-season you gotta do all this and that, fill out this and that...so you're like alright...something else we gotta do. Let's get it done and get the season on with."

Since athletes are accustomed to meeting NCAA mandates, they did not perceive the NCAA SCT screening policy as different from any of the other guidelines or physical examinations to which they had to consent to play collegiate athletics. Athletes were willing to do whatever it took to play their respective sports-even if it meant having a genetic test.

\section{Health Education}

Athletes were ambivalent about SCT testing in the preparticipation sports physical. However, they also desired health education related to the SCT, and feedback following their SCT screening. In reflecting on the pre-participation sports physical process, athletes stated that they wished to learn about the screening tests as well as the results of the pre-participation physical. The following quote illustrates the dominant sentiment among athletes regarding the need for health information:

"People actually need to know what
they're getting their blood taken for
instead of saying... well you probably
don't have it but we gotta do it anyway
type of thing. That's the biggest thing.
Nobody really knew [what we were being
tested for]. We just kinda did it.”

Athletes approached the pre-participation physical as something to get out of the way and viewed themselves as, 'going through the motions.' Nonetheless, many suggested that they wished to to be more knowledgeable about the SCT, and the potential consequences of the examination. This desire, however, was tempered by their anxiety around learning more about the SCT and their potential personal risk:

"I think they should really tell you what you are being tested for because last year when they told me I had to get a sickle cell test, I was like 'what am I gonna do'?....and they were like 'mostly black people get it, and I was like...oh ok...well I'm good then...I don't need to worry about anything.' But they tell you what it is and tell you the symptoms and you're like 'oh that could be [bad]'!”

\section{Perceptions of SCT and NCAA SCT Testing}

Race and discrimination were pertinent to the discussions with athletes since the SCT, and therefore the consequences 
of positive SCT testing, primarily affects African Americans. Athletes expressed no knowledge of the negative history of SCT testing as it relates to race. Regarding the role of race on their sports teams, African American athletes thought they would not experience discrimination as long as they offered value to the team:

"I say no they're [African American and Caucasian athletes] not treated different because it's on the basis of whether or not you're good at your sport. If you play football and you're African American or Caucasian and you're good at your sport and you're on billboards and stuff they are gonna treat you the same. It's just like on a level of how good you are.”

Although African American athletes did not perceive blatant racism, they recognized that race played a role in the circulation of stereotypes around specific roles in their sports. To illustrate this point, an African American athlete suggested, "You don't see too many Caucasian defensive backs in football at any level. That's just how it is. That's how society has the sport set up.”

Therefore, African American participants generally perceived being black in college athletics not as a hindrance or source of discrimination, but as a protective factor. They felt that they, as African Americans, were essential to college sports and that the coaches and athletic directors were well aware of that fact. As such, a diagnosis of the SCT was not perceived as something that would keep them from playing. On the other hand, athletes had limited awareness of the SCT as a health or a racial issue, which may have limited their ability to evaluate its potential ramifications.

\section{Communication Conflict and Fear of Lost Playing Time}

When injuries and health problems arose, athletes weighed carefully what information to disclose to coaches and trainers, to the degree that they were able. Athletes shared that they were not always forthcoming about their health with coaches for fear that revealing health problems would result in lost playing time. They were conflicted on this point, and recognized that there were many good reasons to fully disclose information to coaches and trainers. However, athletes overwhelmingly agreed that they would receive less playing time if coaches knew of health issues and that this was an important consideration when they decided what information to share:

"When I came in [to the athletic program] I had knee problems, I had ankle problems, I had shoulder problems and I knew that but they [coaches and athletic trainers] didn't know. I'm not going to volunteer my injuries."

Playing on a team at the Division I NCAA level was a point of pride and realized ambition for most and, in many cases, was also a source of funding for college studies. As such, exclusion from play was a severe consequence viewed with substantial anxiety by the athletes. When asked explicitly about the potential consequences of a positive SCT test, athletes agreed that a positive test could result in lost playing time, a severe consequence from their vantage point. In this vein, athletes held negative perceptions of the SCT, not because of the clinical implications of the disease, but because of the perceived effect a diagnosis might have on playing time. When asked how they would feel if they were diagnosed with the SCT, participants overwhelmingly responded, "Screwed!" In addition, athletes speculated that they might be viewed differently if found to carry the SCT.

"I would feel upset because that means that I would be looked at differently and even though I may say I'm okay...if the trainer doesn't think I'm okay...I still have to sit out...and just sitting out, you feel like you're useless sometimes."

The fear of being useless and having to sit out during events was strong. In addition, athletes acknowledged the loss of control that occurs when a positive SCT test is shared with coaches and trainers.

\section{DISCUSSION}

The purpose of this study was to explore college athletes' perceptions of the SCT and NCAA SCT testing policies in order to determine potential implications of SCT screening in the context of organized sports.

Most athletes held misconceptions about the SCT. This result is not surprising given that there is a generally low level of awareness about the SCT among the general population in the U.S. (Treadwell, 2006) and is consistent with the findings of other studies focused on similar populations. Ogamdi (1994) found that, like the athletes in our sample, the college students in their study incorrectly believed that the SCT can become SCD. This lack of knowledge about the SCT found among college athletes has implications for the structure of SCT-related policies designed for college athletes. For example, the incorrect belief that only Black athletes may be affected by the SCT may lead non-Black athletes to make uninformed decisions about SCT testing, or neglect to seek out education and information about the SCT.

The present results suggested that many athletes were unaware that they had been tested for the SCT because it was masked by the extensive routine pre-participation sports physical. In addition, athletes had not considered the potential implications of a positive SCT result either inside or outside of the context of sport. These findings are relevant since SCT screening is not an inherently benign activity, especially in the absence of adequate education on the SCT. Given the potential racial, social, financial, and emotional consequences for athletes who test positive for the SCT, education and counseling should be incorporated into the testing process (Treadwell, 2006). Additional support should be offered to those who test positive for the SCT. Quick (2012) showed that SCT carriers were unaware of exertional sickling, making them less likely to take 
precautions to minimize risk. These findings also highlight ethical issues regarding informed consent, autonomy, and privacy of health information that have not been adequately discussed in this context.

Consistent with the findings of another study (Schroeder, 2010), athletes felt pressure to restrict communication of health issues, as they were able, to protect playing time. Concealing health information can negatively impact health of athletes. An athlete with the SCT, for example, should be forthcoming about any symptoms that they may feel during heavy physical exertion in order to receive extra recovery time from coaches or trainers. Interventions designed to protect athletes from health hazards often rely on self-report of early signs of trouble; their effectiveness is undercut by pressure felt by athletes to stay on the field. On the other hand, if athletes with the SCT are limited by coaches and trainers more than necessary, this has a range of negative consequences for the athlete.

Study participants identified race-related stereotypes within athletics (i.e., "Black girls sprint, White girls run long distance”). Notably, though, being African American was seen as a protective factor for some of the African American athletes, who considered that they were "needed" in their sport. They felt that this was also true even for those who might be diagnosed with the SCT. These findings are in contrast to those of another study (Harper, 2009) which found that African American athletes believed that they were treated differently on campus and in athletics and also felt that they had less opportunity to rise to leadership positions within athletics. Although study participants recognized race-related stereotypes within athletics, they seemed completely unaware of the history of race and racialized notions as they pertain to SCT screening. Since SCT primarily affects African Americans, it is imperative that college health professionals be cognizant of these race related stereotypes and anticipate how they might affect athletes' decisions regarding testing and perceptions of the SCT screening process.

\section{CONCLUSIONS}

In sum, the issue of mandatory SCT testing in the NCAA is fraught with challenges and paradoxes, and there is need for further discussion on the part of athletes, coaches, trainers, and officials. These findings set forth possible implications of NCAA-mandated SCT testing, as expressed in the words of Division 1 NCAA athletes at a southern university.

Study limitations include the small number of participants, due to limited availability. Nevertheless, various perspectives by sex, sport, and race were obtained, and study themes were reiterated across focus groups. Focus groups are limited by their social and normative nature and their low capacity to assess correlation and causation. The study was mixed-method, however, and related quantitative findings are reported elsewhere (Lawrence \& Shah, 2014). The findings may not transfer to universities with different athletic cultures and student demographics. While results are not necessarily generalizable to all NCAA governed athletics programs, they do provide insight into issues related to SCT screening for athletes at large Division I schools and highlight the need for discussions and research about the social and behavioral dimensions of SCT testing among athletes. In addition, an examination of the likelihood that SCT testing in the college athletic setting can achieve its public health goals is needed.

Future studies should expand this work to include NCAAgoverned athletics programs of varying size and from diverse locations. More work is needed to determine the experiences of athletes who have tested SCT-positive as well as the experiences of their coaches and the athletic trainers who treat them. Finally, SCT screening policies and procedures of NCAA governed universities should be critically examined to ensure that athletes with the SCT are adequately protected from unintended discrimination.

Acknowledgements: The authors wish to thank Dr. Cassandra Arroyo Johnson for her guidance during the conceptualization of this study. We would also like to thank the athletic trainers and athletes who allowed us a glimpse into athletic culture. Without them, this study would not have been possible.

\section{References}

Acharya, K., Benjamin, H. J., Clayton, E. W., \& Ross, L. F. (2011). Attitudes and Beliefs of Sports Medicine Providers to Sickle Cell Trait Screening of Student Athletes. Clinical Journal Of Sport Medicine, 21(6), 480-485

ATLAS.ti. Version 6.2. (2010) [Computer software] Berlin: Scientific Software Development.

Bonham, V. L., Dover, G. J., \& Brody, L. C. (2010). Screening student athletes for sickle cell trait - a social and clinical experiment. The New England Journal of Medicine, (11), 997.

Brousseau, D. C., Panepinto, J. A., Nimmer, M., \& Hoffmann, R. G. (2010). The number of people with sickle-cell disease in the United States: national and state estimates. American Journal of Hematology, 85(1), 77-78. doi:10.1002/ajh.21570

Connes, P., Reid, H., Hardy-Dessources, M. D., Morrison, E., \& Hue, O. (2008). Physiological responses of sickle cell trait carriers during exercise. Sports Medicine, 38(11), 931-946.

Delgado, R., \& Stefancic, J. (2001). Critical race theory : an introduction. New York : New York University Press.

Eichner, E. R. (2011). Sickle Cell Considerations in Athletes. Clinics In Sports Medicine, 30 (Primary Care Sports Medicine: Updates and Advances), 537-549. doi:10.1016/j.csm.2011.03.00

Elmariah, H., Garrett, M. E., De Castro, L. M., Jonassaint, J. C., Ataga, K. I., Eckman, J. R., \& ... Telen, M. J. (2014). Factors associated with survival in a contemporary adult sickle cell disease cohort. American Journal of Hematology, 89(5), 530535. doi:10.1002/ajh.23683

Grant, A. M., Parker, C. S., Jordan, L. B., Hulihan, M. M., Creary, M. S., Lloyd-Puryear, M. A., \& ... Atrash, H. K. (2011). Public health implications of sickle cell trait: a report of the CDC meeting. American Journal Of Preventive Medicine, 41(6 Suppl 4), S435-S439. doi:10.1016/j.amepre.2011.09.012

Green, L. W., \& Kreuter, M. W. (2005). Health program planning: An educational and ecological approach (pp. 227-253). New York: McGraw-Hill.

Harmon, K. G., Drezner, J. A., Klossner, D., \& Asif, I. M. (2012). Sickle cell trait associated with a RR of death of 37 times in National Collegiate Athletic Association football athletes: a database with 2 million athlete-years as the denominator. British journal of sports medicine, 46(5), 325-330.

Harper, S. R. (2009). Race, interest convergence, and transfer outcomes for Black male student athletes. New Directions for Community Colleges,2009(147), 29-37. 
Harrelson, G. L., Fincher, A. L., \& Robinson, J. B. (1995). Acute exertional rhabdomyolysis and its relationship to sickle cell trait. Journal of athletic training, 30(4), 309.

Hassell, K. L. (2010). Population estimates of sickle cell disease in the US. American journal of preventive medicine, 38(4), S512S521.

Hill, S. (1994). Motherhood and the obfuscation of medical knowledge: The case of sickle cell disease. Gender and Society, 8(1), 29-47.

Hosick, M. B. (2010). Protocol decided for sickle cell testing. The NCAA News.

Jordan, L. B., Smith-Whitley, K., Treadwell, M. J., Telfair, J., Grant, A. M., \& Ohene Frempong, K. (2011).

Hemoglobinopathies: Screening U.S. College Athletes for Their Sickle Cell Disease Carrier Status. American Journal Of Preventive Medicine, 41 (Supplement 4), S406-S412. doi:10.1016/j.amepre.2011.09.014

Kark, J. A., Posey, D. M., Schumacher, H. R., \& Ruehle, C. J. (1987). Sickle-cell trait as a risk factor for sudden death in physical training. The New England Journal of Medicine, 317(13), 781-787.

Kerle, K. K., \& Nishimura, K. D. (1996). Exertional collapse and sudden death associated with sickle cell trait. American family physician, 54(1), 237-240.

Kirk, J., \& Miller, M. L. (1986). Reliability and validity in qualitative research. Sage.

Koopmans, J., Cox, L. A., Benjamin, H., Clayton, E. W., \& Ross, L. F. (2011). Sickle cell trait screening in athletes: pediatricians' attitudes and concerns.Pediatrics, 128(3), 477-483.

Lawrence, (2010). Athlete and coach knowledge, attitudes, and perceptions of sickle cell trait and national collegiate athletic association mandated testing:recommendations for intervention.

Lawrence, \& Shah, G. H. (2014). Athletes’ Perceptions of National Collegiate Athletic Association-Mandated Sickle Cell Trait Screening: Insight for Academic Institutions and College Health Professionals. Journal of American College Health, 62(5), 343350.

Lincoln, Y. S., \& Guba, E. G. (1985). Naturalistic inquiry (Vol. 75). Sage.

Markel, H. (1992). The stigma of disease: implications of genetic screening. The American journal of medicine, 93(2), 209-215.
National Heart Lung and Blood Institute. What is sickle cell anemia? Accessed 09/20/15.

Ogamdi, S. O. (1994). African American students' awareness of sickle cell disease. Journal of American College Health, 42(5), 234-236.

Quick, H. R. (2012). Privacy for Safety: The NCAA Sickle-Cell Trait Testing Policy and the Potential for Future Discrimination. Iowa Law Review, 97(2), 665-691.

Schommer, K., Menold, E., Subudhi, A. W., \& Bärtsch, P. (2012). Health risk for athletes at moderate altitude and normobaric hypoxia. British Journal Of Sports Medicine, 46(11), 1-5.

Schroeder, P. J. (2010). A Model for Assessing Organizational Culture in Intercollegiate Athletic Departments. Journal Of Issues In Intercollegiate Athletics, 98-118.

Scott, R. B. (1982). US Air Force revises policy for flying personnel with sickle cell trait. Journal of the National Medical Association, 74(9), 835.

Sickle Cell Disease Association of America, Inc. Accessed 09/20/15 from http://www.sicklecelldisease.org/

Strecher V, Rosenstock, I (1996). The health belief model. In: Glanz K, Rimer BK (Eds), Health behavior and health education: theory, research, and practice. San Francisco, California: Jossey-Bass.

Thompson, A. A. (2013). Sickle cell trait testing and athletic participation: a solution in search of a problem?. Hematology / The Education Program Of The American Society Of Hematology. American Society Of Hematology. Education Program, 2013632-637. doi:10.1182/asheducation-2013.1.632

Treadwell, M., McClough, L., \& Vichinsky, E. (2006). Using qualitative and quantitative strategies to evaluate knowledge and perceptions about sickle cell disease and sickle cell trait. Journal Of The National Medical Association, 98(5), 704-710.

U.S. Congress, Office of Technology Assessment. (1990). Genetic Monitoring and Screening in the Workplace, OTA-BA-455 (Washington, DC: U.S. Government Printing Office, October 1990).

Wailoo, K. (2001). Dying in the city of the blues : sickle cell anemia and the politics of race and health. Chapel Hill : University of North Carolina Press, [2001]. 